\title{
Is one path enough? Multiple paths and path interaction as an extension of path dependency theory
}

\author{
Anna Bergek and Ksenia Onufrey
}

Linköping University Post Print

Tweet

N.B.: When citing this work, cite the original article.

Original Publication:

Anna Bergek and Ksenia Onufrey, Is one path enough? Multiple paths and path interaction as an extension of path dependency theory, 2014, Industrial and Corporate Change, (23), 5, 12611297.

http://dx.doi.org/10.1093/icc/dtt040

Copyright: (C) The Author 2013. Published by Oxford University Press on behalf of Associazione ICC. All rights reserved.

http://icc.oxfordjournals.org/

Postprint available at: Linköping University Electronic Press

http://urn.kb.se/resolve?urn=urn:nbn:se:liu:diva-102614 


\title{
Is one path enough? Multiple paths and path interaction as an extension of path dependency theory
}

\author{
Anna Bergek*and Ksenia Onufrey**,
}

\begin{abstract}
In order to explain the development of multi-technology companies and industries where several alternative technologies co-exist and interact over long time periods, this paper suggests an extension of path dependency theory by providing a conceptualization of the path notion which incorporates the theoretical possibility of multiple paths and path interaction. The conceptualization is applied to a patent study of three leading companies in the lighting industry: General Electric, Osram/Siemens and Philips. The study shows technology development patterns that are characterized by strong persistence, both within each path and across the whole technology field. These results demonstrate that multiple technological paths can co-exist in companies and industries, characterized by simultaneous long-term presence of several technologies. In such cases, path interaction takes place both between co-existing paths and when new, radically different paths are created. Although further studies are needed to identify the underlying self-reinforcing mechanisms, there is a clear indication that technological path dependency is not restricted to unitary progression patterns, as implied by previous conceptualizations.
\end{abstract}

\section{Key Words:}

Path dependency, multiple paths, path interaction, technological persistence, lighting industry, patent data

\section{Introduction}

The research efforts devoted to understanding industry and technology dynamics have led to a development of the concept of technological path dependency. In recent years, this concept has been used to explain the process of cumulative, sequential technological development characterized by persistence (Fai, 2003; Cantwell and Vertova, 2004) and self-reinforcing mechanisms (Araujo and Harrison, 2002; Garud et al., 2010). Apart from literature on economics of technology and innovation, the path dependency concept in its broader form has also been applied in historical sociology and economic geography.

However, even though the process of path dependency has been intensively researched, the concept of 'path' has received much less attention. Paths are usually implicitly conceptualized as

*Anna Bergek, Department of Management and Engineering and KITE Research Group, Linköping University, SE-581 83 Linköping, Sweden. e-mail: anna.bergek@liu.se.

**Ksenia Onufrey, Department of Management and Engineering, Linköping University, SE-581

83 Linköping, Sweden. e-mail: ksenia.onufrey@liu.se.

tCorresponding author. 
persistent patterns in the development of a technology, a company or an industry (Cowan and Gunby, 1996; Rycroft and Kash, 2002; Sydow et al., 2009). Even if the early stages of path dependency allow for some degree of variety, by later phases there is only one path left; the number of alternative choices gradually decreases (David, 1985; Arthur, 1989; Cowan and Gunby, 1996) until companies or entire industries become locked-in to one - often inferior option, e.g. a technology (Unruh, 2000; Vergne and Durand, 2010).

In the study of technological path dependency, this conceptualization works well if one particular technology is in focus (e.g. Mazzoleni, 1997). However, it is insufficient when it comes to explaining the development of multi-technology companies or industries characterized by long-term co-existence of alternative technologies, with dominant designs within each technology and evidence of interaction between these technologies. According to current path dependency theory, such companies and industries cannot be described as path dependent, since they are not pursuing one, single path. However, a close scrutiny of empirical data shows that they can indeed possess the main features of path dependency: persistence and selfreinforcing mechanisms. We would, therefore, argue that the theory of technological path dependency should be adapted in order to be able to take them into account.

The purpose of this paper is to extend the theory of technological path dependency by providing a conceptualization of the path notion, which incorporates a theoretical possibility of multiple paths and path interaction. We, thereby, join Dobusch and Schüßler's (2012) recent call for a broader conceptualization of the path dependency concept. Our conceptualization is applied to an empirical setting in order to identify multiple technological paths in an industry where several alternative technologies have developed over time and continue to co-exist: the lighting industry. Based on a study of patent data of three industry leaders (General Electric (GE), Osram/Siemens and Philips), we show that technology development in the lighting industry progresses along largely parallel technological paths. We also show that there are different kinds of interaction between paths, in particular in the form of simultaneous use of different classes in the same patents and use of classes associated with 'older' technologies in patents that are related to more recently developed technologies.

Overall, all the outlined patterns are characterized by strong persistence, both within each path, and across the whole technology field. This applies to individual firms and to the industry as a whole. Although further studies are needed to identify the underlying self-reinforcing mechanisms, our analysis thus gives a clear indication that technological path dependency is not restricted to single path patterns.

\section{Path dependency and multiple path progression}

\subsection{Paths in previous path dependency research}

David (1985) suggested the notion of path dependency to describe a change process affected by remote, and sometimes chance, events. Since then, a theory of path dependency has been developed, growing from a simple idea that "history matters" to a complex concept, constituting an important part of the evolutionary view of technological change. The concept of path

dependency has, however, also been adopted by several other scientific disciplines and has been applied at several different levels of analysis, from the micro-level of firms, through the mesolevel of technological fields and industries to the macro-level of institutions (Vergne and Durand, 
2010). The current understanding of technological path dependency describes it as an accumulation of competences and activities into a persistent and stable pattern (Fai, 2003), driven by self-reinforcing processes that, in the absence of external shocks, lead to an irreversible state of inflexibility (Vergne and Durand, 2010).

In spite of a growing number of articles devoted to path dependency, including several recent attempts to summarize and formalize the concept (Garud et al., 2010; Vergne and Durand, 2010), the path itself has received relatively little conceptual attention although a large number of applications of the concept are found at different levels of analysis. Since the focus of this paper is technological rather than organizational or institutional paths, the following review is limited to literature on technological path dependency. Similar path concepts can, however, be found in other parts of the path dependency literature as well.

In several of the classic articles on technological path dependency, a path is a winning technology or dominant design. For example, Arthur (1989) suggests that a path is created through sequences of choices between competing technologies, such as light-water vs. heavywater nuclear power reactors or crystalline- vs. amorphous-silicon solar photovoltaic cell technologies. Similarly, Cowan and Gunby (1996) describe competition between different types of agricultural pest control technologies as choices between different paths and Mazzoleni (1997) discusses the selection of open- and closed-loop numerically controlled machine tool designs in Japan and the US respectively. In a related tradition, paths are thought of as technological trajectories or paradigms, within which technologies develop over time, constrained by physical, cognitive, normative and regulative borders (cf. Dosi, 1982).

More recent studies of technological path dependency have focused on paths as repeated choices and actions with regard to technology. Micro level studies in this tradition tend to focus on the knowledge bases and competencies of individual firms. Paths are described as persistent (or repeated) choices about which domains of competence to develop in a firm and what problems to focus on, caused by "local" learning and search processes (Lei et al., 1996; Teece et al., 1997; Karim and Mitchell, 2000; Rosenkopf and Nerkar, 2001; Danneels, 2002; Rycroft and Kash, 2002; Antonelli, 2009). This can be empirically observed in terms of stable portfolios of technologies within firms (Patel and Pavitt, 1997; Fai, 2003) or close relationships between technology and product diversification patterns (Laursen, 1996). ${ }^{1}$

Another part of the literature analyzes technological path dependency in industries and innovation systems. Here, the main focus is persistence in terms of stable patterns of technological and industrial specialization of sectoral, regional and national innovation or production systems. For example, Fai and von Tunzelmann (2001) show that the technological profiles of a number of industrial sectors are characterized by long-lasting specificity; Martin (2010) relates path dependency to various forms of localized forms of industrial specialization; Essletzbichler and Winther (1999) demonstrate that the Danish food processing industry is characterized by persistent regional differences in production technologies; and Narula (2002) argues that technological specialization patterns vary between national innovation systems and exemplifies this with the case of the Norwegian national innovation system, with its stable

\footnotetext{
${ }^{1}$ In the broader path dependency literature, micro-level paths include persistent choices with regard to productmarkets (Helfat and Raubitschek, 2000; Danneels, 2002), business models (Schreyögg et al., 2011) and innovation approaches (Thrane et al., 2010; Park, 2011).
} 
specialization in low-technology, resource-based sectors (cf. also Niosi, 2002; Rycroft and Kash, 2002; Cantwell and Vertova, 2004; Boschma and Frenken, 2006; Storz, 2008; Fagerberg et al., 2009). ${ }^{2}$

As this overview shows, the technological path concept is primarily associated with persistence, either in the form of irreversible choices between competing (and mutually excluding) technologies or in the form of technological specialization patterns which are studied at a quite aggregate level, for example in the form of technology portfolios of firms or countries. This stands in stark contrast to the weight placed in recent literature on identifying self-reinforcing mechanisms (Dobusch and Schüssler, 2012), which requires a more specific definition and delineation of each path under study. Moreover, in spite of the fact that some of the path dependency literature seems to be open to the possibility that several different paths may coexist across companies, industries, regions and countries and that co-existing paths can influence each other, current path dependency literature does not provide any framework that can handle this. In the following, we therefore propose a framework that both captures the current understanding of path dependency as a combination of persistence and self-reinforcing mechanisms and extends it to include the notions of multiple paths and path interaction.

\subsection{Conceptualizing paths: progression types and path dependency}

In order to illustrate and explain the suggested extension of path dependency theory, we use Van den Daele's (1969) typology of progressions as a starting point. This typology provides a general representation of sequential change processes characterized by emergent properties, such as developments along a path. It distinguishes between (a) cumulative and simple progression, (b) conjunctive and disjunctive progression and (c) unitary and multiple progression (see Figure 1). ${ }^{3}$ As we clarify in more details in the following sub-sections, the first two dimensions of this typology capture the most two central features of path dependency - persistence and selfreinforcing mechanisms - while the third dimension addresses the focus of this study: the dynamics of multiple paths and path interactions. Thus, the main advantage of this framework is that it covers both the current understanding of technological path dependency and the suggested extension and relates them to a more general understanding of progression patterns. The typology has also been used to conceptualize innovation processes previously, most notably by Poole et al. (2000), but its application to path dependency theory is new.

\footnotetext{
2 In the broader path dependency literature, industry-level conceptualizations include, for example, overall innovation trajectories followed by entire industries (D'Costa, 2002). Macro-level studies of path dependency are also common in the fields of historical sociology and political science. In this literature, path dependency is described at the level of complex societal systems. A primary focus in this literature is the path dependent character of institutions, including legal systems and other regulatory frameworks (Martin, 2010). Here, paths are defined in terms of institutional persistence, i.e. stable institutional patterns that have deterministic properties or are locked in for considerable periods of time (Mahoney, 2000; Martin, 2010). Two examples are the dominance of markets and large firm corporate capitalism in the US (Schneiberg, 2007) and persistence of competition regimes in the US and Germany (Djelic and Quack, 2007).

3 This typology was developed in the context of developmental psychology and some adaptation has therefore been made to suit the present context.
} 


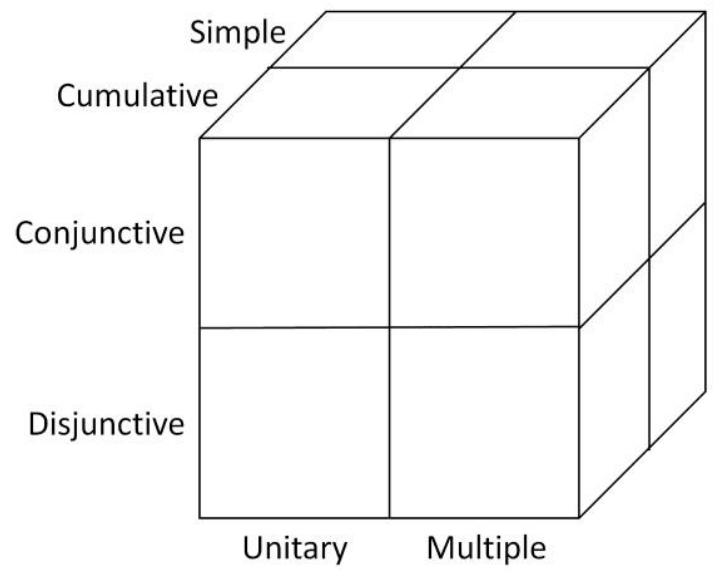

Figure 1. A conceptual model of progression types (adapted from Van den Daele (1969)).

\subsubsection{Cumulative vs. simple progression}

Simple progression implies that there is no carry-over of properties from one sequential step to another (Poole et al., 2000). In contrast, cumulative progression implies that some earlier properties co-exist with some later properties (Van den Daele, 1969). Cumulative progression can be complete, i.e. all earlier properties are carried over, or partial, i.e. characteristics are carried over to a later step but then might "drop off" after a while (Poole et al., 2000). ${ }^{4}$ It stands clear that only cumulative progression can be path dependent; unless current events build further on earlier events, history can hardly be said to matter even in the weakest sense.

The concept of cumulativeness is closely related to the notion of technological persistence, which as described above is an important element of the path concept. Persistence refers to the existence and maintenance of a specific pattern of technological specialization, based on a gradual and cumulative process of competence development (Fai, 2003). In the studies of technological persistence, competence accumulation is seen as a key feature of technological change, with a constraining impact on future search and learning processes (Dosi, 1982; Malerba et al., 1997; Cantwell and Vertova, 2004). Past achievements, patterns of problem-solving activities and accumulated competencies constrain current activities as well as directions in which new opportunities can be searched for (Dosi, 1982; Malerba et al., 1997; Patel and Pavitt, 1997) and new opportunities are therefore likely to be found close to areas of existing expertise (Teece et al., 1997). The result is a stable pattern of technological specialization within a company or an industry (Patel and Pavitt, 1997; Essletzbichler and Winther, 1999; Fai and von Tunzelmann, 2001; Fai, 2003).5

\footnotetext{
4 Partial cumulative progression "is common in organizational contexts because losses of memory, mistakes, and terminated opportunities often occur in complex organizational environments." (Poole et al., 2000: 234)

${ }^{5}$ It should be noted that this definition of persistence differs from that presented in the literature on technological regimes, where persistence refers to stability in terms of who the main innovators are in a sector or industry. There is, however, a connection between the two definitions: "high levels of technological cumulativeness at the firm level are expected to be associated to persistence in innovative activities, a high degree of stability in the hierarchy of innovative firms and a low rate of innovative entry" (Malerba, 2007).
} 


\subsubsection{Conjunctive vs. disjunctive progression}

The conjunctive-disjunctive distinction adds another dimension to progression: the relationship between earlier and later events in a series. In conjunctive progression, events are intrinsically related to each other (Van den Daele, 1969) and derive from a joint, underlying process (Poole et al., 2000). In contrast, disjunctive progression implies that events are unrelated or even separated from each other. Thus, the carry-over from one step to the other is not due to any underlying process - at least not one that can be observed (cf. Van den Daele, 1969).

As earlier described, causal mechanisms between earlier and later events, which in the path dependency literature are commonly referred to as self-reinforcing mechanisms, are a key aspect of path dependency (cf., e.g., Vergne and Durand, 2010; Dobusch and Schüßler, 2012). Self-reinforcing sequences are those which at every step generate consequences "that amplify the impact of the outcomes of the earlier rounds in ensuing rounds, moving sequences of events along ever-narrower paths" (Araujo and Harrison, 2002: 7). ${ }^{6}$ They give a chain of events an "inherent logic" (Mahoney, 2000) and a momentum of its own (Dosi, 1982) rather than merely a stable content over time (i.e. persistence). This means that a path is affected not only by initial conditions or choices, but also by the entire sequence of events along the path (Mahoney, 2000). ${ }^{7}$ Examples of self-reinforcing mechanisms include technological externalities, learning, uncertainty reduction and positive network externalities (Arthur, 1988; Cowan and Gunby, 1996; Vergne and Durand, 2010), but also functional, power, and legitimation mechanisms (Mahoney, 2000) (for an overview of self-reinforcing mechanisms found in previous literature, see Dobusch and Schüßler (2012)).

\subsubsection{Multiple vs. unitary progression}

Finally, progression can be unitary or multiple. Unitary progression excludes alternative development paths, whereas multiple progression implies that several paths co-exist (Van den Daele, 1969). Multiple progression can be parallel (when the number of paths is the same in two successive stages), convergent (when there are fewer paths at a later stage) or divergent (when there are more paths at a later stage). The existence of multiple paths also implies that coexisting paths can be linked to each other and evolve together (Martin, 2010) through learning and recombination of knowledge and other elements between paths (Håkansson and Waluszewski, 2002).

Previous technological path dependency literature primarily looks at paths as a unitary concept. Although the development of a path is often described as a process of convergence, in which one technology is selected among a larger number of alternatives (cf. David, 1985; Arthur, 1988; Cowan, 1990; Cowan and Gunby, 1996), the emergence of a path is clearly related to the point in time when a selection has been made. Paths are, thus, seen as an outcome of technological competition, in which one of the initially available alternatives wins and becomes increasingly irreversible over time (David, 1985). Consequently, lock-in is discussed as a possible outcome of path dependency in the absence of external shocks (Vergne and Durand, 2010).

However, some parts of the technological path dependency literature seem to be more open to the possibility that multiple paths can co-exist. First, some articles mention the existence of

\footnotetext{
${ }^{6}$ Self-reinforcing sequences can be contrasted with "reactive" sequences (or, as Karnøe and Garud (2000) call them, path creation) which can lead to shifting of a path into a new direction (Mahoney, 2000; Araujo and Harrison, 2002).

7 This is what distinguishes path dependency from past dependency (Antonelli, 2009)
} 
bifurcation points or junctures, when alternative future paths appear, which can be interpreted as opportunities for divergent progression (cf., e.g., Araujo and Harrison, 2002). However, most of this literature still adheres to the notion of lock-in and therefore argues that path dependency essentially prevents actors from going down emerging technological paths (Aminzade, 1992; Araujo and Harrison, 2002); lock-in implies that actors lose their ability to adapt to changes and cannot move to other alternatives even if they would prefer to do so (Garud et al., 2010; Vergne and Durand, 2010). This implies that new paths tend to originate from outside existing industries and that industry incumbents can be severely challenged when new technological paths emerge (cf. the literature on discontinuous innovation, e.g. Tushman and Anderson, 1986; Henderson and Clark, 1990; Christensen and Rosenbloom, 1995). In a weaker form of this argument, the choice of which of several possible future paths to take is not completely restricted, but still strongly influenced by the previous pattern of activity (Parker, 2011).

Second, several scholars argue that even if path dependency has a constraining effect on actors, they are still creative and able to influence the course of events, change directions of paths or generate new paths, e.g. through technological diversification (cf. Fai and von Tunzelmann, 2001; Araujo and Harrison, 2002; Antonelli, 2009; Garud et al., 2010). Actors iterate past patterns of thought and action, but they are also able to generate future scenarios and evaluate alternative trajectories in response to changing demands and opportunities (Araujo and Harrison, 2002). In the words of Garud et al. (2010: 770), "[a]ctors mobilize the past not necessarily to repeat or avoid what happened, but, instead, to generate new options" (cf. also Håkansson and Waluszewski, 2002). ${ }^{8}$ However, although this seems to imply that divergent progression is possible, most of this literature still maintains the notion of a unitary path. With the exception of Sydow et al (2012), actors are seldom described as pursuing several paths in parallel. Instead, they shift paths, which entails a break with the past and by definition involves simple and disjunctive progression rather than path dependency.

Third, according to some literature there is some room for alternative paths also when a dominant path has been established. Firms can experiment with technologies that are unrelated to their main product, and at the industry level, technological alternatives can be developed in market niches even though a dominant design has been established (Simmie, 2012). Yet, in this literature there is a clear unbalance between co-existing, multiple paths: one is dominant and the others are of a niche-like character.

Fourth and finally, the innovation systems literature fully acknowledges that technical change takes place within complex socio-technical systems that involve many layers and, consequently, include many alternatives for actors to choose between. However, in empirical studies these multiple technological paths only seem to appear across a population of firms, industries, regions or countries and not within individual entities in this population, i.e. each firm, industry, region or country chooses one path and sticks to that (cf., e.g., Mazzoleni, 1997; Essletzbichler and Winther, 1999; Fai, 2003; Cantwell and Vertova, 2004; Sutherland et al., 2012).

\footnotetext{
8 This agency-oriented perspective resonates well with the so-called Schumpeter Mark II pattern of innovation described by, for example, Malerba et al. (1997). According to this literature, innovation is a result of creative accumulation of technological competencies (Bergek et al., 2013), which is why technological persistence does not inevitably lead to the decrease of the level of innovative activities. Instead, some firms develop dynamic capabilities which help them to "integrate, build and reconfigure internal and external competencies in line with requirements from their external environment" (Teece et al., 1997: 516).
} 
There are, thus, some indices that at least part of the previous literature implicitly acknowledges the existence of multiple technological paths, but we would argue that it does not fully capture either the importance or the extent of multiple path progression since it either sees co-existing paths as mutually exclusive or only allows for alternative paths to co-exist if they are clearly subordinate to a dominant path.

From our perspective, this is problematic for two main reasons. First, as is commonly acknowledged in the technology management literature, many companies can best be described as multi-technology firms, where several, equally important technologies are pursued simultaneously (Granstrand, 1994; Brusoni et al., 2001). This implies that without a more explicit conceptualization of multiple paths, studies risk neglecting persistence and selfreinforcing mechanisms at the level of individual technological trajectories (cf. Dosi, 1982). Second, several recent studies indicate that interaction between co-existing paths can have influential effects on technical and industrial change processes. For example, some multipurpose technologies, such as the Internet, have the potential to affect the development of several paths (Dolata, 2009) and literature on industry convergence seems to suggest that a creative synthesis of several technological paths can generate new paths, e.g. the emergence of 'functional foods' at the boundary between food and pharmaceuticals (cf. Bröring et al., 2006; Curran and Leker, 2011).

In order to handle these problems, path dependency theory needs to include the possibility of multiple paths more explicitly. We therefore suggest the introduction of a broader path concept (see Figure 2). We include the current understanding that both cumulativeness (persistence) and conjunctivity (self-reinforcing mechanisms) are characteristic to path dependency.

However, we extend this understanding and include not only unitary progression and lock-in (Figure 2a), but also multiple progression (Figure 2b). This conceptualization is not restricted to present notions of co-existing paths as described above, but can capture all types of simultaneous progression of several paths, including path creation, industry convergence and parallel multi-path development within companies and industries.

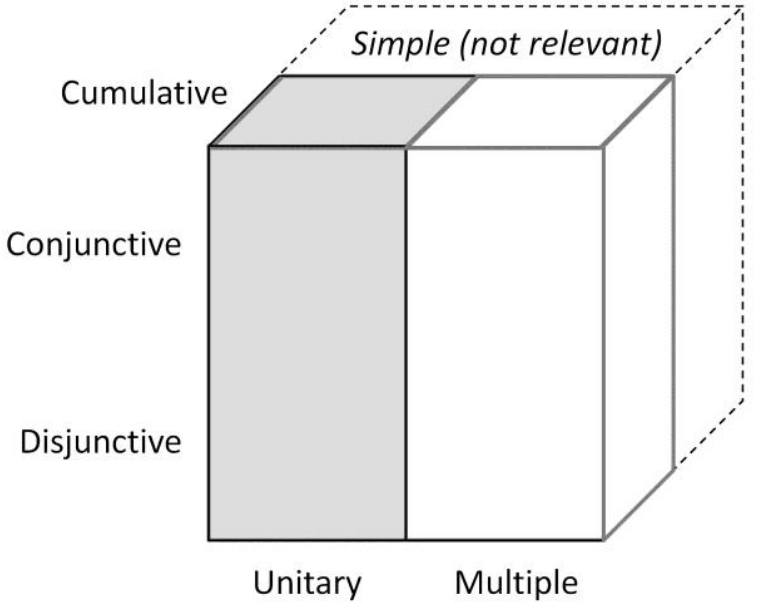

(a)

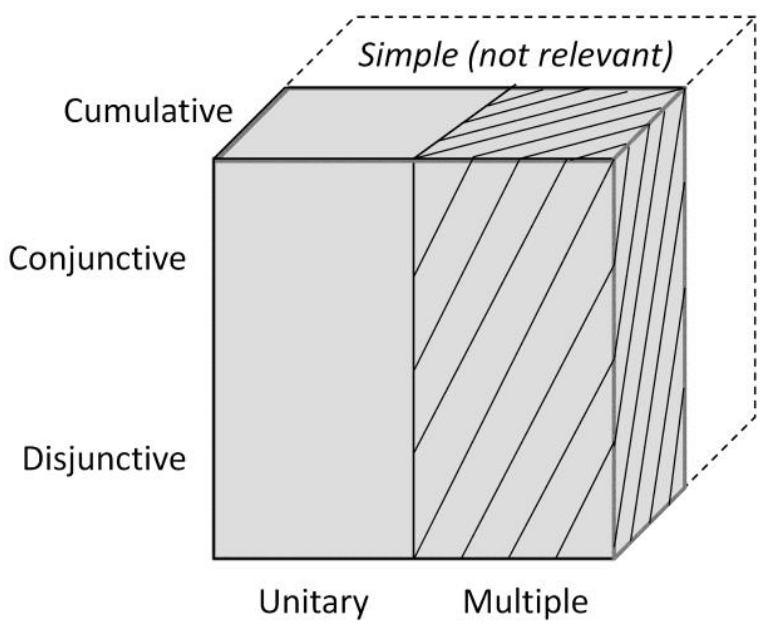

(b)

Figure 2. Progression types and their application in a path dependency context: (a) focus in previous literature (grey area) vs. (b) suggested extended framework (grey area; the striped area is the primary focus of this paper). 
In our empirical case, the lighting industry, we can identify a number of co-existing technologies, most notably incandescent bulbs, discharge lamps, and light-emitting diode (LED) lighting. The three main incumbent actors, GE, Osram/Siemens and Philips, not only participate in all these technologies, but are among the companies leading their development, which seems to be an indication of some kind of industry-level technological persistence and, possibly, path dependency.

In the rest of the paper, we will validate the suggested theoretical framework by applying the multiple-path framework to the case of the lighting industry. In order to do that, we will answer two research questions. The first question investigates whether multiple paths can be identified in a multi-technology empirical context. The existence of multiple technology paths can be confirmed if the three technologies in focus progress largely independent of each other and show signs of cumulative development (i.e. persistence). If these progression patterns are similar across companies within the same industry it would seem to indicate that the path is related to the technology or industry level and not only to individual companies. The second question relates to interaction between co-existing paths. In particular, an important question is to what extent companies can utilize knowledge accumulated in one path as a basis for technological activities in other paths, i.e. if there are signs of cumulativeness between paths.

These research questions will be addressed by analyzing the technological activities of the three leading firms in the lighting industry. Thereby, we hope to contribute to a more thorough understanding of the role of multiple path progression and path interaction in a path dependency context.

\section{Research design and data collection}

\subsection{Overall research design}

As explained in the theoretical section, the notion of path is strongly related to persistence in technologies and technological activities. Therefore, we study technological paths by identifying signs of technological persistence, defined as stable patterns of technological activity. In line with previous literature, we apply patent analysis for this purpose.

According to Fai (2003), patents are an appropriate measure for investigating cumulative (persistent) technological development because they provide data over long time periods and because they usually require comparatively low degree of novelty and, therefore, are able to reflect incremental change processes. This reasoning is also in line with the idea proposed by Patel and Pavitt (1991) that patents measure not only technology generation but also diffusion and imitation that include improvements of the original technology. Patent data have also been frequently used in previous technology and innovation studies as an indicator of technological capabilities and activities (e.g. Patel and Pavitt, 1991, 1997; Fai, 2003; Bergek and Berggren, 2004), which indicates that they form a useful basis for identifying persistent patterns of activities or technological capabilities at the firm level.

The empirical setting to which we apply patent analysis is the lighting industry. Lighting patents filed with the US Trademark and Patent Office (USPTO) over a period of 35 years (1976-2011) are analyzed in order to identify activity patterns that persist over time. The choice of patent database and the specific measures used to study persistence and paths through patents are 
discussed in the following subsections, while general notes on using patent data are summarized below.

The general advantages and disadvantages of patent data are well known (cf. Patel and Pavitt, 1991). The specific methodological issues related to the use of patents in this study are the following. First, the propensity to patent can vary between countries and firms (Patel and Pavitt, 1991). In this study, all three companies are multinational firms active in basically the same markets. Their needs for patent protection to gain or retain industry leadership should, thus, be similar. Nevertheless, we try to reduce any company effect by comparing not only the absolute number of patents in different lighting classes and fields, but also classes' shares in the overall number of lighting patents for each company. Second, it can be difficult to find all patents granted to large firms since they often file patents under the names of their subsidiaries (Patel and Pavitt, 1997). The limited number of companies in this study has, however, made it possible to identify key subsidiaries manually, based on, e.g., annual reports (see further in Section 3.3).

\subsection{Choice of patent database: USPTO}

The analysis is focused on three companies: GE, Osram/Siemens and Philips. These three companies are generally considered to be the global technology leaders in the industry; according to Sanderson et al (2008), each of these companies has more patent applications in traditional lighting technologies than any other firm. We limit the study to these three companies both because of their technological dominance and because of their long historical presence in the industry, which allows us to study technological activity patterns over an extended period of time. The main drawback of this delineation is that LED newcomers are not included in the analysis. However, previous studies of LED show that the big three are key companies in patenting for LED lighting (Woodside Capital Partners International, 2012) and both Osram and Philips are among the leading companies in LED lamps and LED components (Global Industry Analysts, 2011; HSBC Trinkaus\&Burkhardt, 2011). We discuss the implications of this delineation further in the final section of the paper.

Osram/Siemens and Philips are originally European and GE is from the U.S. When constructing our dataset we, thus, had the choice of using either the official patent database of the USPTO or the European Patent Register provided by the European Patent Office (EPO). Both these choices would have implied some bias in the form of possible overrepresentation of "domestic" companies in the dataset (GE in USPTO and Philips and Osram/Siemens in EPO).

We decided to use USPTO for three main reasons. First, using USPTO allows for key-word searches in patent abstracts, which is not possible in EPO. As will be discussed further below, abstract search is an important tool to identify relevant patents for technologies that are not clearly associated with particular classes, such as LED. Second, EPO contains both granted patents and patent applications older than 18 months, in contrast to USPTO that distinguishes clearly between patent applications and issued patents. In order to distinguish between issued patents and patent applications in EPO, we would have needed to open and manually check each patent document. Considering the large number of patents included in our study, this was not practically feasible. Third, using USPTO leads to comparatively lower underrepresentation for the non-domestic companies. All companies have more patents in their domestic databases. However, using USPTO leads to lower underrepresentation of Osram/Siemens and Philips compared to the underrepresentation of GE when using EPO. EPO contains over two times fewer 
GE patents than USPTO while USPTO provides only $8 \%$ less patents of Philips and $24 \%$ less patents of Osram/Siemens than available in EPO. ${ }^{9}$

Thus, we consider USPTO to be more appropriate for this study than EPO, although we acknowledge that this choice might lead us to underestimate the technological activities and capabilities of Osram/Siemens and, to a lower extent, Philips in comparison with GE. However, since the focus of this study is persistence in technological activities rather than the relative amount of patents of the three companies, this possible underestimation is not crucial for the results of this study.

\subsection{Dataset}

We started building our dataset by identifying patent classes related to lighting technology. Patent classes are hierarchically organized groups of patents. Every patent is assigned to a number of classes (at least one, but usually several), which correspond to the patent's technical content. We used the International Patent Classification (IPC), which contains a complex classification structure from a section to a subgroup. In the following, we refer to 4-character length groupings (e.g. H01J) as classes and to the level below as sub-classes. An initial choice of classes was made based on Osram's patent portfolio, since Osram, unlike Philips and GE, is fully specialized on lighting. Class names and descriptions of the most frequently used classes in Osram's patents were checked in the IPC and complemented with classes used in previous studies of lighting (Sanderson et al., 2008) and classes identified through the IPC - Standard Industrial Classification (SIC) concordance by Silverman (2004). The search strategy was constructed at the level of patent sub-classes (see Appendix A for details). In the analysis, patents are grouped at the level of classes in order to find higher-level patterns.

As a complement to this class-based search, we searched for specific keywords in patent titles and abstracts. We applied two groups of keywords. The first group was used to cross-check the results of the class-based search and consisted of the following main keywords: "lighting", "lamp" and "light source". The second group of keywords was intended to search for LED-related patents and consisted of different variations of writing LED ("LED", "light emitting diode", "lightemitting diode" etc.). LED technology is not associated with a specific patent class, which is why this keyword search became a key part in identifying LED-related patents. A similar approach was also used in Sanderson et al (2008).

The resulting search strategy (see Appendix A) was applied for GE, Osram/Siemens, Philips and their subsidiaries. Key subsidiaries were identified based on annual reports of GE, Siemens and Philips (for at least 15 years) where major active subsidiaries as well as key joint ventures and acquisitions were mentioned. We assumed that subsidiaries found in the annual reports were of strategic importance for the companies and should be included in the analysis. Subsidiaries were included in the analysis from the year of acquisition.

\footnotetext{
${ }^{9}$ For the calculations mentioned above the search was performed only in five patent classes available in both databases: H01J, H05B, F21, H01K, C09K. We did not include keywords search since possibility to search in patent abstracts (apart from titles) makes results biased towards USPTO. The class 26 was not included either as it is not used in EPO. Additionally, since EPO contains both issued patents and patent applications, for USPTO we combined search results from patent database and applications database. Searches for this comparison were performed in April 2012.
} 
The complete USPTO database includes patents from 1790 to present time. However, as described above, our search strategy was dependent in part on keyword searches, which could only be performed in the full-text database of patents applied for since 1976. Before that, only images of patents are available, which restricts searches to patent numbers and classification codes. Ideally, a study of persistence should cover the entire time period from the origin of an industry, in order to fully trace the emergence and development of the technological paths under study, but we consider 35 years (1976-2011) to be a sufficiently long period of time to be able to determine whether activity patterns are stable or not.

Results from patent class and keyword searches were combined, and all duplicates were removed. ${ }^{10}$ For each patent, the following information was obtained: patent number, title, issue date, inventors, assignee, application number, filed date, US and international classes, US and foreign references. In total, 7,614 patents are included in our main dataset, out of which:

- 2,133 patents are assigned to GE and its subsidiaries

- 2,305 patents are assigned to Osram/Siemens and its subsidiaries

- 3,176 patents are assigned to Philips and its subsidiaries

It should be noted that there are comparatively few Osram/Siemens patents before the mid1990s. The number is low both compared to the number of Osram/Siemens patents after the mid-1990s and to the number of Philips and GE patents before the mid-1990s. The same pattern was observed in both USPTO and EPO. After consulting annual reports, web-based material and company contacts, we have still not been able to find any apparent explanation for this lack of patents in the period of 1976-1995.

\subsection{Indicators and measurements}

In the analysis, we use three main groups of indicators of technological persistence: indicators of persistence at an aggregated level, indicators of persistence inside narrowly defined technological paths and indicators of interaction between paths (see Table 1).

The first set of indicators represents an overall lighting path by measuring persistence at an aggregated level. We analyze the companies' lighting patent portfolios in order to see if they are stable over time in terms of the relative shares of different patent classes, with particular focus on the development trends of 'traditional' patent classes, i.e. classes that have been used throughout the entire time period under study. We also look at two more specific indicators of cumulative progression: (a) to what extent 'newer' technologies are categorized in patent classes related to 'older' technologies, which is an indicator of the technological relatedness (cf. Breschi et al., 2003) between them, and (b) the extent to which patents refer to previous lighting patents, which is an indicator of whether new knowledge builds on existing knowledge.

These indicators are quite traditional ways of studying persistence. However, for the specific purpose of our study, it is not sufficient to identify an overall path. We also need to be able to look below the aggregated level of the lighting technology field as a whole and distinguish multiple technological paths as well as the interaction between them. The second and third

\footnotetext{
${ }^{10}$ Data gathering was performed in March 2012; all patents issued later than 2011 were deleted.
} 
groups of indicators have been chosen for this purpose: the second set represents narrowly defined technological paths (by measuring persistence within each of them) and the third set measures interaction between these narrow paths.

Before we can describe the specific indicators we, however, need to operationalize the path concept with regard to our specific empirical setting. We define a path as a persistent progression pattern inside a more or less independent stream of technological activities. In the patent system, such streams of technological activities are represented by patent classes, as described above. In this study, we focus on identifying three narrowly defined technological paths that correspond to three technologies: incandescent bulbs, discharge lamps and LED. Two of these are directly associated with corresponding patent classes: incandescent bulbs (H01K) and discharge lamps (H01J). As mentioned previously, the third technology, LED, is not associated with any particular class; the patent class which is most closely related to LED patents (Semiconductor devices - H01L) is broad and apart from LED patents also contains semiconductor and electric solid state device patents which are largely unrelated to the lighting industry. In order to analyze the LED path, we therefore use patents derived from the keyword search as previously described.

It should be noted that we do not consider patent classes (or groups of patents identified through keyword searches) to represent paths by default, just because they correspond to specific technologies. Instead, the issue of persistence or cumulativeness is key to identifying a path. Our second set of indicators therefore includes (a) references to patents in the same class (incandescent and discharge) or specific group of patents (LED), which measure the extent to which the patents associated with a narrowly defined technology build on each other, and (b) simultaneous use of two or more sub-classes of the same class in one patent, ${ }^{11}$ which shows interconnections between different knowledge areas within a narrowly defined path.

The third set of indicators measures interaction between narrowly defined paths: (a) simultaneous presence of the technology-specific classes associated with incandescent bulbs or discharge lamps in the same patent and (b) presence of these classes in patents related to LED.

\section{Table 1. Indicators of persistence}

\begin{tabular}{ll}
\hline Group of indicators: what is measured & Indicators \\
\hline $\begin{array}{l}\text { Persistence within an overall lighting } \\
\text { path }\end{array}$ & - $\begin{array}{l}\text { patent shares and development trends of traditional } \\
\text { classes }\end{array}$ \\
& - $\begin{array}{l}\text { presence of traditional classes in patents related to } \\
\text { newer technologies } \\
\text { share of references to companies' own lighting } \\
\text { patents }\end{array}$ \\
$\begin{array}{l}\text { Persistence inside multiple } \\
\text { technological paths }\end{array}$ & $\begin{array}{l}\text { patent references within narrowly defined lighting } \\
\text { technologies }\end{array}$ \\
& $\begin{array}{l}\text { references to patents that belong to the same } \\
\text { class }\end{array}$ \\
& references of LED patents to other LED \\
patents
\end{tabular}

\footnotetext{
11 We refer to the first class mentioned in the Class field of a patent as the first class, and all the following classes as secondary classes.
} 
- simultaneous use of two or more sub-classes of the same main class in one patent

- simultaneous presence of different technologyspecific classes in the same patents

- presence of traditional classes in patents related to the new technology

When applying these indicators, we first analyze the patents of each company separately and, thus, measure persistence at the company level. At the industry level, technological persistence is measured by identifying similarities in patenting patterns across companies and by analyzing an aggregated set of patents (i.e. by considering patents of all three companies simultaneously).

\section{The lighting industry: technology and market overview}

The global lighting industry consists of three main sectors - general lighting, automotive lighting and backlighting - with revenues of EUR 52 billion, 13 billion and 4 billion, respectively (McKinsey\&Company, 2011). General lighting can be further divided into light sources (or lamps), control gears and ballasts, lighting controls and luminaires (or fixtures). The focus of this paper is the light source segment, which contributes with $24 \%$ of the revenues of the general lighting sector (HSBC Trinkaus\&Burkhardt, 2011).12

The light source segment can be seen as a specific technological field, where several distinct technologies have been developed over time. Today, three main technologies can be distinguished: incandescent, discharge and LED. This is the most general distinction, and the first two technologies can be subdivided further (see Table 2). The three main lighting technologies differ considerably from each other in terms of underlying principles for light generation. In that sense, the LEDs, which were initially used as electronic components, are closer to the semiconductor field than to the other two lighting technologies.

Table 2. Light source technologies and sub-technologies

\begin{tabular}{ll}
\hline Main technology & Sub-technologies \\
\hline Incandescent & Incandescent bulbs \\
& Halogen lamps \\
Discharge & Low-pressure discharge lamps (e.g. linear and compact fluorescent lamps) \\
& High-pressure discharge lamps
\end{tabular}

${ }^{12}$ Although the study is mainly focused on the light source segment, the patent collection process cannot fully account for the differences between segments. Therefore, the following should be noted:

1. Patents related to luminaires can be included into the dataset. However, most of such patents are considered to belong to the class 26 (Industrial design) and, therefore, have been separated at the early stage of the analysis

2. Patents related to automotive lighting can be included into the dataset, however, since general and automotive lighting patents are not separated at the level of patent classes and since all three analyzed companies produce automotive lamps, this inclusion should not affect the results

3. Backlighting patents are included into the dataset, however, the number of these patents is very low compared to the rest (according to keyword check), and most of them belong to traditional lighting classes 
The overall distribution of the general lighting market between these technologies in terms of unit sales and sales value is presented in Table 3. Incandescent lamps still dominate the market in terms of the number of lamps sold each year, whereas compact fluorescent (low-energy) lamps have the largest share in terms of sales value. So far the market penetration of LED in the lighting market is still limited, especially in terms of unit sales. However, in 2011, LED-based sales accounted for $16 \%$ of the total lighting sales of Philips (Philips, 2011) and $25 \%$ of the total sales of Osram (Osram, 2012) ${ }^{13}$ and LED is expected to become the dominant technology in 10 years (HSBC Trinkaus\&Burkhardt, 2011). These expectations are based on the fast rates of development and diffusion of LED technology as well as on the needs for more energy efficient and environment friendly technologies. Today, the lighting industry is responsible for $19 \%$ of global electricity consumption and $6 \%$ of global $\mathrm{CO}_{2}$ emissions (HSBC Trinkaus\&Burkhardt, 2011) and many countries, including the EU, Brazil, Russia, the U.S., China, India and Japan are introducing programs intended to phase-out incandescent lamps (McKinsey\&Company, 2011).

Table 3. Shares of different technologies in the worldwide general lighting market

\begin{tabular}{lll}
\hline Lighting Technology & $\begin{array}{l}\text { Market share } \\
\text { (units, \%) }\end{array}$ & $\begin{array}{l}\text { Market share } \\
\text { (value, \%) }\end{array}$ \\
\hline Incandescent & 52 & 12 \\
Halogen & 12 & 10 \\
Linear fluorescent lamps (LFL) & 16 & 19 \\
Compact fluorescent lamps (CFL) & 17 & 31 \\
HID & 2 & 14 \\
LED & 1 & 14 \\
\hline
\end{tabular}

Note: Market data include all main application areas: residential, commercial, industrial and outdoor. Source: McKinsey \& Company (2011)

For decades, the lighting industry has been dominated by three companies that together have a global market share of over 60\%: Philips (25\%), Osram/Siemens (21\%) and GE (14\%) (Global Industry Analysts, 2011). Philips and Osram dominate the European market, with about 30-40\% of the market each in comparison with GE's 5-10\% (European Commission, 2011). GE is the U.S. market leader with a market share of 33\%, although Philips and Osram are close behind with $29 \%$ and $25 \%$ respectively (IBISWorld, 2012).

\section{Evidence of technological persistence in the lighting industry}

In this section, we analyze our dataset using the indicators of technological persistence and path interaction described in the methodology part. First, we focus mainly on the indicators of an aggregated path. Next, we show evidence of multiple paths and path interaction.

\footnotetext{
${ }^{13}$ We have not been able to find corresponding numbers for GE.
} 


\subsection{Persistence within the overall lighting path}

\subsubsection{Patent shares and development trends of traditional classes}

The total number of classes in the dataset is about 200 and each company has patents in about 120 of these classes. Since we primarily used class-based search when gathering data, it is not surprising that the six classes that were included in the search are rated among the most frequently used for all the three companies (see Table 4). It is noteworthy, though, that the topthree classes are the same for all three companies. They account for more than half of all the analyzed patents. The top-seven classes account for more than $70 \%$ of the patents in the dataset. 14

Another interesting observation is that a class that was not included in the class-based search appeared quite high among the most frequently used classes: H01L - Semiconductor devices. As was explained in the methodology section, we did not include it into the search strategy due to its broad content. Instead, we used keywords when searching for LED-related patents. The H01L class is nevertheless ranked among the top 6 classes in the main dataset for all three companies.

Table 4. Top-10 most frequent patent classes (first class checked)

\begin{tabular}{|c|c|c|c|c|c|c|c|}
\hline \multirow[t]{2}{*}{ Class } & \multirow[t]{2}{*}{ Class description } & \multicolumn{3}{|c|}{ Number of patents } & \multirow{2}{*}{$\begin{array}{l}\text { Average } \\
\text { rank }\end{array}$} & \multirow{2}{*}{$\begin{array}{l}\text { Per cent } \\
\text { share }\end{array}$} & \multirow{2}{*}{$\begin{array}{l}\text { Cumu- } \\
\text { lative } \\
\text { share }\end{array}$} \\
\hline & & GE & $\begin{array}{l}\text { Osram/ } \\
\text { Siemens }\end{array}$ & Philips & & & \\
\hline H01J & $\begin{array}{l}\text { Electric discharge tubes or } \\
\text { discharge lamps }\end{array}$ & 526 & 574 & 734 & 1 & $24 \%$ & $24 \%$ \\
\hline H05B & $\begin{array}{l}\text { Electric heating; Electric lighting } \\
(\ldots)\end{array}$ & 343 & 394 & 601 & 2 & $18 \%$ & $42 \%$ \\
\hline F21 & Lighting & 272 & 256 & 351 & 3 & $11 \%$ & $53 \%$ \\
\hline H01L & $\begin{array}{l}\text { Semiconductor devices; Electric } \\
\text { solid state devices (...) }\end{array}$ & 80 & 148 & 170 & 5 & $5 \%$ & $58 \%$ \\
\hline C09K & Materials for applications $(\ldots)$ & 116 & 131 & 117 & 5 & $5 \%$ & $63 \%$ \\
\hline 26 & $\begin{array}{l}\text { International classification for } \\
\text { industrial designs: } 26 \text { - Lighting } \\
\text { apparatus }\end{array}$ & 42 & 117 & 243 & 6 & $5 \%$ & $68 \%$ \\
\hline H01K & Electric incandescent lamps & 98 & 81 & 147 & 6 & $4 \%$ & $72 \%$ \\
\hline G02B & $\begin{array}{l}\text { Optical elements, systems, or } \\
\text { apparatus }\end{array}$ & 28 & 28 & 57 & 10 & $1 \%$ & $74 \%$ \\
\hline H01R & $\begin{array}{l}\text { Electrically-conductive connections } \\
(\ldots)\end{array}$ & 30 & 42 & 33 & 11 & $1 \%$ & $75 \%$ \\
\hline H02M & $\begin{array}{l}\text { Apparatus for conversion between } \\
\text { ac and ac, between ac and dc (...) }\end{array}$ & 40 & 19 & 46 & 12 & $1 \%$ & $77 \%$ \\
\hline
\end{tabular}

\footnotetext{
14 These shares are high not only in the combined dataset, which theoretically could be caused by extreme domination of these classes in one of the companies, but are approximately equally high in each company dataset: the share of top-three classes is $53 \%$ at each company, and the share of top-seven classes is varies between $69-74 \%$ among the three companies.
} 


\begin{tabular}{|c|c|c|c|c|c|c|c|}
\hline $\mathrm{C03C}$ & Chemical composition of glasses (...) & 34 & 26 & 32 & 13 & $1 \%$ & $78 \%$ \\
\hline G01N & $\begin{array}{l}\text { Investigating or analysing materials } \\
\text { by determining their chemical or } \\
\text { physical properties }\end{array}$ & 24 & 31 & 15 & 15 & $1 \%$ & $79 \%$ \\
\hline G02F & $\begin{array}{l}\text { Devices or arrangements, the optical } \\
\text { operation of which is modified by } \\
\text { changing the optical properties of } \\
\text { the medium of the devices (...) }\end{array}$ & 12 & 15 & 53 & 16 & $1 \%$ & $80 \%$ \\
\hline G03B & $\begin{array}{l}\text { Apparatus or arrangements for } \\
\text { taking photographs (...) }\end{array}$ & 61 & 7 & 40 & 17 & $1 \%$ & $81 \%$ \\
\hline G05F & $\begin{array}{l}\text { Systems for regulating electric or } \\
\text { magnetic variables }\end{array}$ & 7 & 31 & 35 & 17 & $1 \%$ & $83 \%$ \\
\hline
\end{tabular}

A more detailed analysis of the most frequent patent classes shows that in addition to the classes that refer to particular technology types (H01K - Incandescent lamps, H01J - Discharge lamps, H01L - Semiconductor devices), there are also more general lighting classes (F21 - Lighting, H05B - Electric lighting, 26 -Lighting apparatus (industrial design class)), and one broader class (C09K - Materials for applications).

Taken together, these data show a common patenting pattern for all three companies. However, in order to talk about industry-level technological persistence and an overall industry path, this pattern should be traced over time. Figure 3 shows how the shares of the most frequent patent classes have developed over time. ${ }^{15}$ Most of the classes (apart from H01L - Semiconductor devices) can be described as "traditional", considering that they have been present throughout the whole period of analysis (and in many cases long before that). In the following, we will analyze the dynamics of these classes in more detail. ${ }^{16}$

The combined share of the five traditional lighting classes decreased from about $60 \%$ in 1976 1980 to about 50\% in 2007-2011. Although the observed trend is declining, traditional classes retained a significant part of all patents in the dataset (see Figure 3). H01J - Discharge lamps has the largest share throughout almost the whole period, although its share has decreased steadily over the last 15 years. H01K - Incandescent lamps also shows a decreasing trend and holds less than one per cent of patents in recent years. As for the general lighting classes, H05B - Electric lighting and F21 - Lighting both have slightly increasing shares in the end of the studied period, but they differ in terms of dynamics over the years: H05B has two considerable spikes, while F21 has a more stable development pattern, with a decrease in the end of the 1990s. The last traditional class, C09K - Materials for applications, has a small but stable patent share between 1976 and 2004, with a decrease at the end of the studied period.

\footnotetext{
15 When analysis of class usage over time is performed, patent issue date is usually used as the time indicator in order to avoid bias related to the fact that up to several years can be needed from patent application to patent issue. All applied but not approved (issued) patents are not added into the dataset and consequently this would be reflected as a declining trend in the number of patents during several latest years if plotted per application date.

${ }^{16}$ It should be noted that one of these classes, 26, represents lighting design patents which do not directly reflect the development of the lighting technologies. Therefore, further analysis will not include the 26 class.
} 


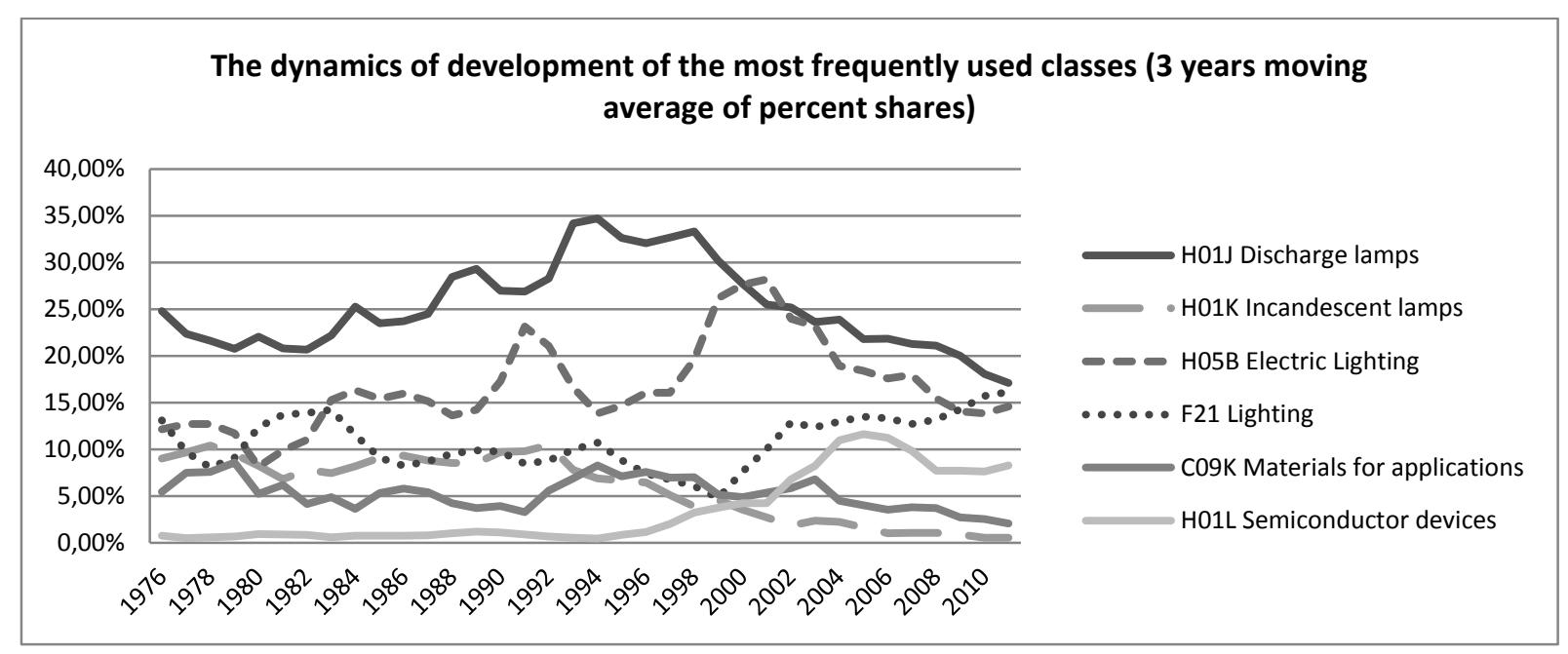

Figure 3. Shares of most frequently used patent classes (first class only)

Thus, from the dynamics of patent shares we can see a downward trend for several traditional lighting classes since the end of 1990s. However, if we look at the absolute number of patents in these classes for the same period the picture changes. Figure 4 illustrates the dynamics of the absolute numbers of patents in the traditional lighting classes since the end of 1990s. The total number of patents submitted in these five classes every year is considerably higher in 20072011 (on average 219 patents per year) than in 1997-2001 (on average 158 patents per year). The absolute numbers also show more stable and even growing trends for individual classes. H01J - Discharge lamps and two general lighting classes (H05B and F21) are growing. C09K Materials for applications is stable and even the decline of class $\mathrm{H} 01 \mathrm{~K}$-Incandescent lamps is less drastic, compared with the decline in relative numbers.

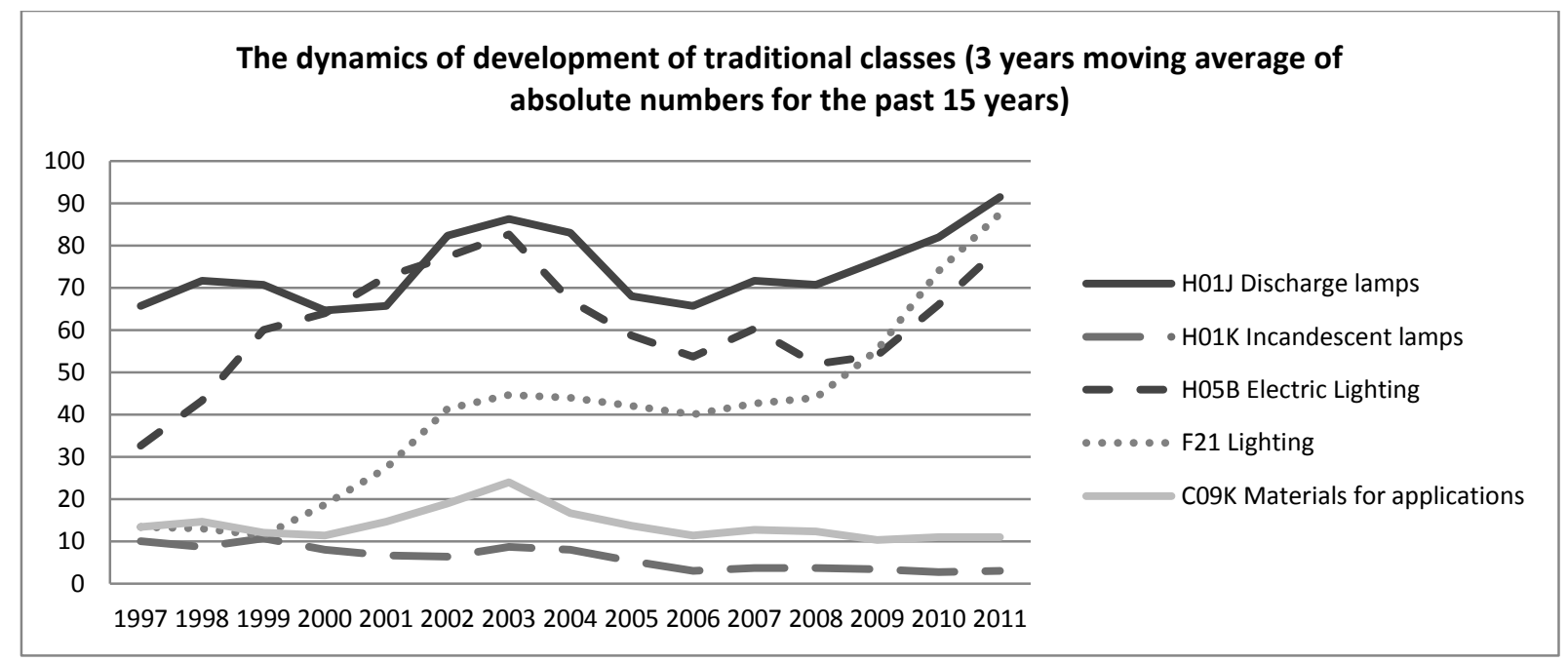

Figure 4. Development dynamics of traditional lighting classes for the past 15 years

In summary, we can conclude that there is technological persistence and an overall path at the industry level, which is demonstrated by stability of lighting shares of the general lighting classes (H05B and F21) and stable or growing trends in the absolute numbers of patents of four of five traditional classes (H01J, H05B, F21, C09K). 
In order to see whether technological persistence can be observed at the company level as well, Figures 5-9 represent the development dynamics of the traditional lighting classes, plotted separately for each company. ${ }^{17}$ In order to obtain a more complete picture of how the traditional classes were used by the companies over time, the figures below include all patents where these classes were used (not only as the first class), which implies that the sum of all shares may add up to more than $100 \%$.

Figures 5-9 show that the patterns found at the industry level are also valid at the company level. Class H01K - Incandescent lamps is slowly decreasing, with quite similar dynamics over the past 10 years for all the three companies. Class H01J - Discharge lamps is quite stable over time. Class F21 - Lighting is stable at GE, but at the same time shows a considerable growth at Philips and Osram/Siemens. Class H05B - Electric lighting is growing steadily at

Osram/Siemens, is quite stable at GE, and shows general growth with a considerable peak in the beginning of 2000s at Philips. Class C09K - Materials for applications shows quite uneven dynamics for all three companies, but generally a positive trend can be noticed.

Based on these patterns, we can conclude that there is technological persistence at the company level. The similarity in the dynamics of patent classes between these three companies also strengthens our arguments regarding industry-level persistence. Although it is too early to discuss persistence inside narrowly defined paths (since the corresponding indicators have not been applied yet), the fact that each class has a unique pattern over time serves as the first indirect indication that different technologies have their own development dynamics rather than follow a common logic.

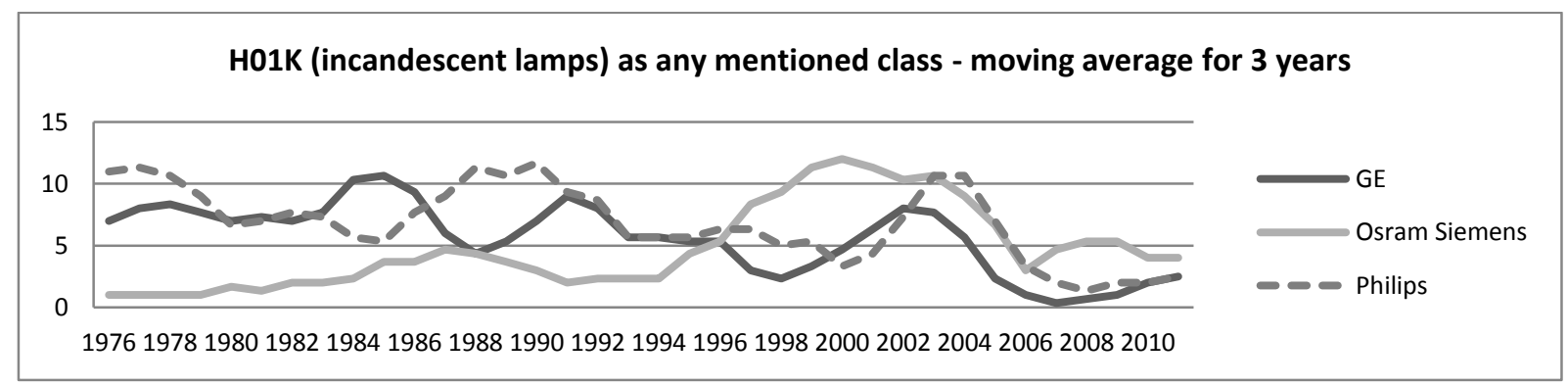

Figure 5. HO1K class at GE, Osram/Siemens and Philips

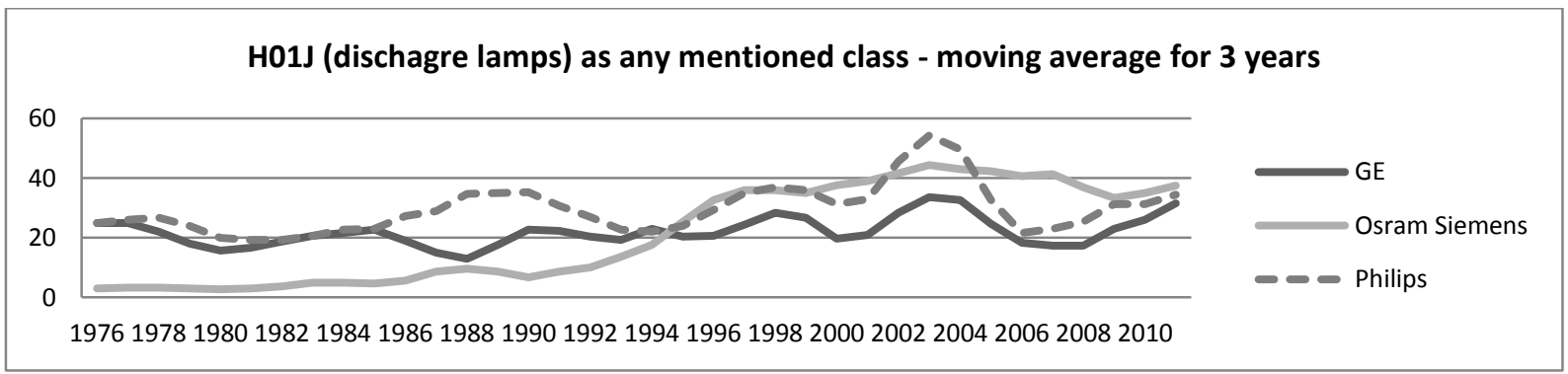

Figure 6. HO1J class at GE, Osram/Siemens and Philips

\footnotetext{
${ }^{17}$ As was mentioned in Section 3, a low number of patents were found at Osram/Siemens before the mid-1990s, which explains why the curves for H01K and H01J at Osram/Siemens go up in the second half of the observed period.
} 


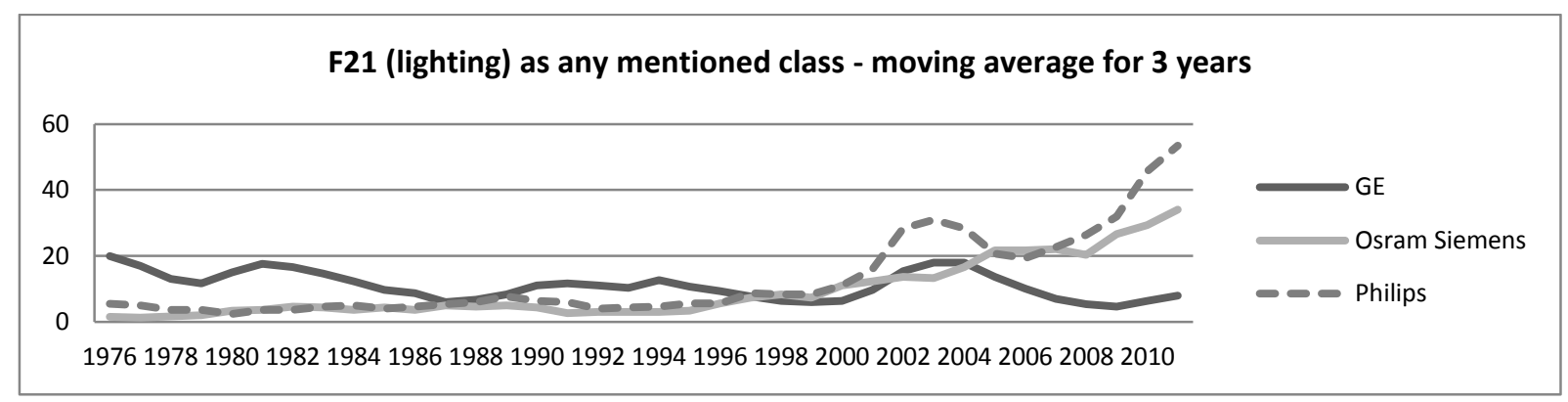

Figure 7. F21 class at GE, Osram/Siemens and Philips

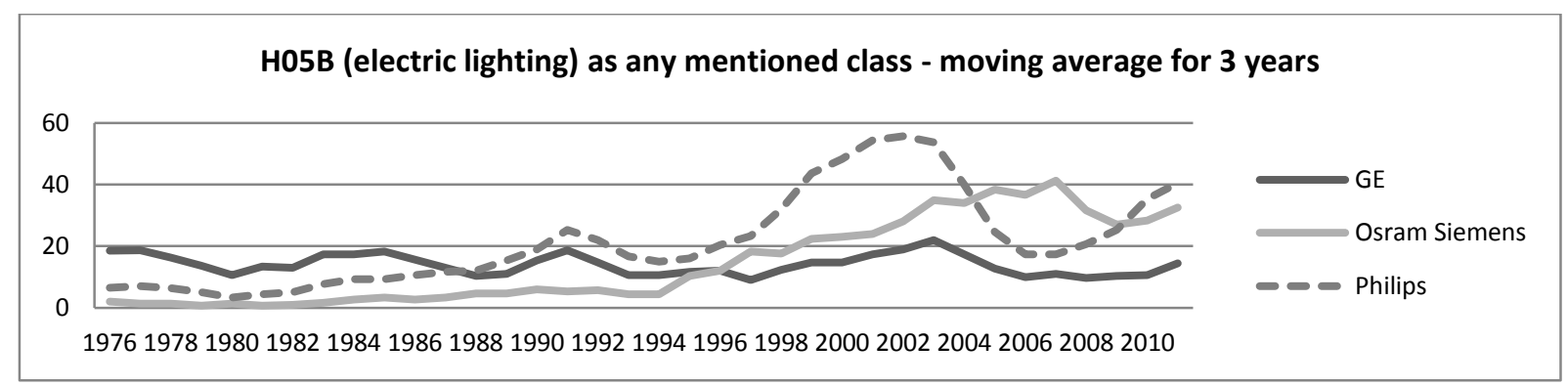

Figure 8. HO5B class at GE, Osram/Siemens and Philips

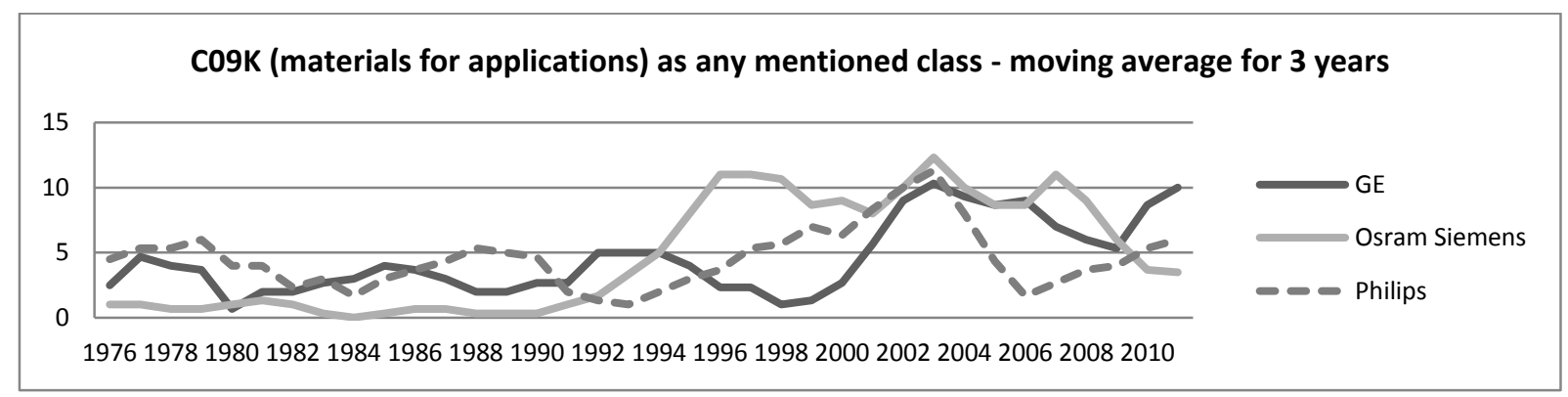

Figure 9. CO9K class at GE, Osram/Siemens and Philips

\subsubsection{Traditional classes in patents related to a new technology}

The most recently added technology (LED) requires separate attention. Many LED-related patents belong to the class H01L - Semiconductor devices. ${ }^{18}$ The development of the H01L class reflects the decision of the lighting industry incumbents to join the LED technology which was pioneered by new entrants in the late 1990s. The fact that a new major class was added into the companies' patent portfolio points to the discontinuous character of the new technology. However, $30-40 \%$ of the patents identified as LED-related in our keyword search still belong to traditional lighting classes (see Figures 10-12). Such extensive use of traditional lighting classes in LED-related patents indicates that previously accumulated expertise has been important for the development of LED technology, in spite of its discontinuous character. This also points to the cumulative character of technological development in the lighting industry and the presence of an aggregated lighting path.

\footnotetext{
${ }^{18}$ As we have clarified in the methodology section, we could not base our search of LED-related patents on H01L class since it is a broad class that contains not only LED-related patents. However, among lighting patents, H01L patents tend to belong to the LED technology.
} 
The pattern observed at the industry level can also be seen at the company level, although with some differences between the three companies. Over the entire studied period, GE shows the highest technological persistence with 39\% of the LED-related patents making use of traditional classes. However, GE's LED technology development shows a downward trend after an initial peak in the beginning of the 2000s (see Figure 10). The charts of Philips and Osram/Siemens seem similar in terms of both timing and scale of activities (see Figures 11-12). Over the entire studied period, Philips seems slightly more technologically persistent in their LED patents (36\%) than Osram/Siemens (33\%). Additionally, both companies show upwards trend in the recent years.

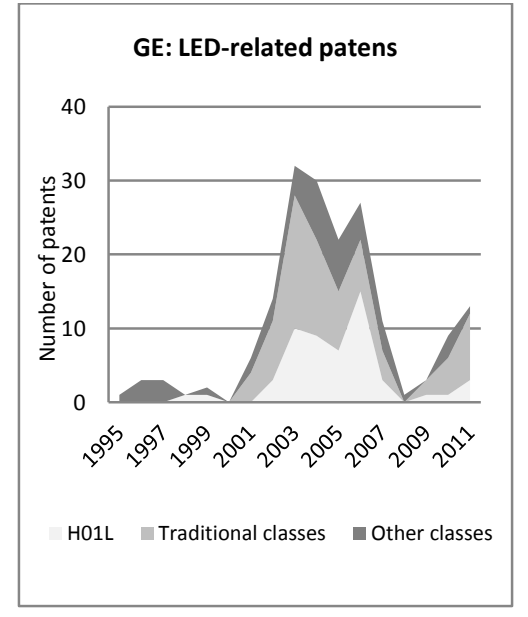

Figure 10. LED patents at GE

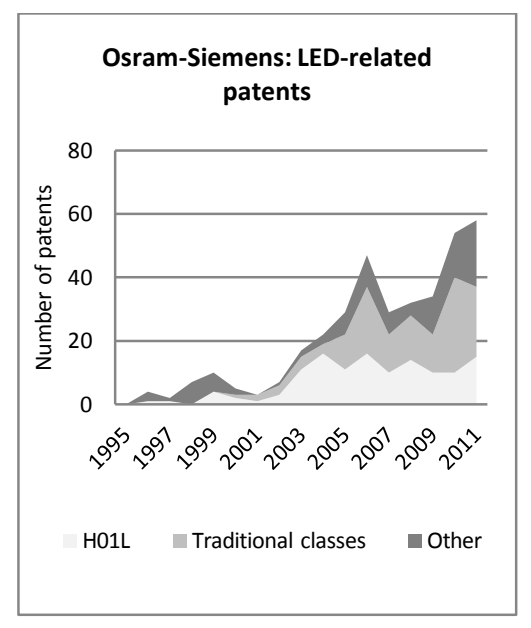

Figure 11. LED patents at Osram/Siemens

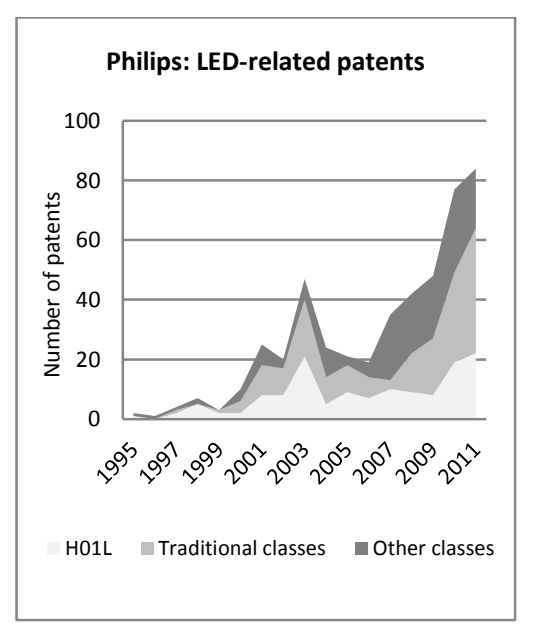

Figure 12. LED patents at Philips

Note: percentages in the above text are provided for the whole studied period (1976-2011), while the charts represent the period 1995-2011, since a very low number of LED -related patents were submitted before 1995 .

\subsubsection{References to companies' own lighting patents}

The analysis of patent references shows that when the three companies refer to their own patents, they primarily refer to other lighting patents and not to patents related to any of the other business areas in which these multi-technology companies are active (e.g. power generation, electronics or medical equipment). For example, about $80 \%$ of references to own patents at GE are references to the company's lighting patents, and this share is even more striking - about $90 \%$ - at Osram/Siemens and Philips. This is an indicator of persistence at an aggregate level of the lighting technology field as a whole. Here, we can talk about persistence both at company and industry levels, since the trends are equally strong for all the three companies.

\subsection{Persistence inside multiple technological paths}

\subsubsection{Patent references within narrowly defined lighting technologies}

As described in the methodology section, three narrowly defined technological paths are investigated in this study - incandescent, discharge and LED. Since the first two technologies have corresponding patent classes (H01K and H01J, respectively), the analysis of these two 
paths is class based. Since the LED technology lacks a single corresponding patent class, patents that belong to this technology have been grouped based on keywords.

The first indicator of persistence inside these narrowly-defined technological paths measures the extent to which patents refer to other patents that belong to the same technology. In case of class-based technologies, we check if $\mathrm{H} 01 \mathrm{~K}$ and H01J patents refer to other patents of the same class. In case of LED, we check if LED patents tend to refer to other LED patents.

The analysis shows that for all three technologies over $70 \%$ of patents that refer to companies' own lighting patents refer to patents that belong to the same technology. Moreover, as we can see in Table 5, approximately the same holds even when a patent cites one of the other two incumbents' lighting patents (for example, when GE cites patents of Osram/Siemens or Philips). The observed tendency to refer to patents within the same technology is a clear sign of persistence inside narrowly defined paths. The patenting pattern discussed in relation to traditional lighting classes showed persistence in the form of stable, persistent use of particular patent classes, which could be seen as one, overall unitary path. However, persistence in the form of a dominance of internal citation dynamics inside each technology is a strong indicator of the existence of largely independent development trajectories, which allows us to identify the analyzed patent groups as parallel, multiple paths.

Table 5. Analysing patent references

\begin{tabular}{|c|c|c|c|}
\hline Items for comparison & GE & $\begin{array}{l}\text { Osram/Siemen } \\
\text { s }\end{array}$ & Philips \\
\hline Share of patents having references to own lighting patents & $40 \%$ & $34 \%$ & $40 \%$ \\
\hline $\begin{array}{l}\text { Share of H01K patents that refer to company's own } \mathrm{H} 01 \mathrm{~K} \\
\text { patents (among those referring to own lighting patents) }\end{array}$ & $74 \%$ & $82 \%$ & $77 \%$ \\
\hline $\begin{array}{l}\text { Share of H01J patents that refer to company's own H01J } \\
\text { patents (among those referring to own lighting patents) }\end{array}$ & $79 \%$ & $80 \%$ & $84 \%$ \\
\hline $\begin{array}{l}\text { Share of LED patents that refer to company's own LED } \\
\text { patents (among those referring to own lighting patents) }\end{array}$ & $77 \%$ & $75 \%$ & $85 \%$ \\
\hline $\begin{array}{l}\text { Share of patents having references to the other two } \\
\text { incumbents' lighting patents }\end{array}$ & $25 \%$ & $36 \%$ & $24 \%$ \\
\hline $\begin{array}{l}\text { Share of } \mathrm{H} 01 \mathrm{~K} \text { patents that refer to the other two incumbents' } \\
\text { H01K patents (among those referring to their lighting } \\
\text { patents) }\end{array}$ & $71 \%$ & $64 \%$ & $71 \%$ \\
\hline $\begin{array}{l}\text { Share of H01J patents that refer to the other two incumbents' } \\
\text { H01J patents (among those referring to their lighting patents) }\end{array}$ & $81 \%$ & $79 \%$ & $75 \%$ \\
\hline $\begin{array}{l}\text { Share of LED patents that refer to the other two incumbents' } \\
\text { LED patents (among those referring to their lighting patents) }\end{array}$ & $82 \%$ & $76 \%$ & $69 \%$ \\
\hline
\end{tabular}

Note: we could check only first 8-10 references of each patent due to cell length limitations in Excel. However, since we analyzed shares of references (in section 5.1.3) and shares of patents (Table 5) rather than absolute numbers, this limitation is not considered to have a major impact on our results. 


\subsubsection{Simultaneous use of two or more sub-classes of the same main class in one patent}

Patents frequently belong to several classes simultaneously which provides an additional way to check the presence of internal dynamics for class-based paths. ${ }^{19}$ Table 6 shows pair wise use of classes. The first column of the table represents the first classes that correspond to incandescent (H01K) and discharge (H01J) technologies, while the rest of the columns represent most frequent secondary classes. It should be noted that only patents having two or more classes are included in this part of the analysis.

As can be seen from the values in bold text in Table 6, for both analyzed technologies secondary sub-classes belong to the same first class in over $80 \%$ of the cases. Similar patterns can be observed for each of the companies taken separately. Taken together, the cumulative pattern and a general similarity between company-level patterns can be interpreted as an additional sign of industry-level persistence inside narrowly defined multiple paths.

Table 6. Pairwise usage of classes (first class vs. secondary classes)

\begin{tabular}{|c|c|c|c|c|c|}
\hline $\begin{array}{l}\text { Secondary class } \\
\text { First class }\end{array}$ & H01J & H01K & H01L & H05B & F21 \\
\hline H01J Discharge lamps & $81 \%$ & $8 \%$ & $0.4 \%$ & $9 \%$ & $3 \%$ \\
\hline H01K Incandescent lamps & $52 \%$ & $94 \%$ & $0 \%$ & $0.3 \%$ & $5 \%$ \\
\hline
\end{tabular}

\subsection{Interaction between paths}

Analysis of simultaneous usage of patent classes can also serve as an indication of interaction between paths. As Table 6 shows, $52 \%$ of the patents having H01K - Incandescent lamps as the first class have H01J - Discharge lamps as one of their secondary classes, which is an indication of interdependency between the incandescent and discharge technological paths. Taking this interdependency into account, it would be easy to assume that patents having H01J as the first class frequently refer to $\mathrm{H} 01 \mathrm{~K}$ patents, since incandescent lamps were developed chronologically earlier than discharge lamps. However, only $8 \%$ of H01J patents refer to $\mathrm{H} 01 \mathrm{~K}$ patents. This indicates that an interaction between different paths is not straightforward and cannot be explained simply by the chronology of the appearance of technologies.

As for the evidence of interaction between the LED path and other technologies, two observations can be made. First, some insights can be derived from the above analysis of the LED technology. The analysis in section 5.2 identified LED as the most recently added technological path. Although it differs considerably from the older ones, it still shows signs of interaction with previous activities in the form of usage of traditional classes. Second, $8 \%$ of LED patents belong to at least one of the two technology-specific classes (H01K or H01J), which is a direct indication of interconnection between, on the one hand, the LED path, and on the other hand, the incandescent and discharge paths. Taking into account that LED is typically described

\footnotetext{
19 The same analysis cannot be applied to the LED technology since patens related to this technology have been identified based on keywords, and not patent classes
} 
as a major break with past activities in the lighting industry, even this relatively low share points to the existence of cumulative progression between paths.

Another interesting observation with regard to path interaction can be made if we look at all patents submitted by three analyzed companies that have H01L (Semiconductor devices) as the first class (in this case, we check patents submitted by all businesses of these multi-technology corporations, and not only their lighting subsidiaries). For all three companies, the total number of $\mathrm{H01 \textrm {L }}$ patents is much higher than the number of their H01L patents that relate to lighting: 186 patents in total at GE vs. 80 at GE lighting, 387 vs. 148 for Osram/Siemens and 385 vs. 170 for Philips. This confirms that all three companies use semiconductor technology in other applications than lighting, which implicitly supports the assumption that technological interaction across business units is possible in multi-technology companies.

\section{Conclusions and suggestions for further research}

By means of a study of patent data related to three leading companies in the lighting industry, this article has shown that multiple technological paths exist and that path interaction takes place in companies and industries characterized by long-term co-existence of multiple technologies.

Our empirical analysis showed that persistence is characteristic to each of the three analyzed companies as well as to the lighting industry as a whole. At the company level, evidence of technological persistence and an overall lighting path was found in the form of (a) sustained use of a number of traditional classes throughout the entire period of study, (b) use of these classes across all technologies, including the recently added LED technology, and (c) limited reference to company-internal patents outside the lighting field. At the industry level, the evidence of persistence is also strong. The company patterns are very similar in almost every aspect of our analysis: the same classes dominate for all companies, they patent at about the same level in terms of the number of patents in each class and the dynamics of the patenting patterns of the companies are almost the same, with the possible exception of LED. The technological persistence described above is, thus, not only a company-level phenomenon, but common to all three industry incumbents. These findings complement previous literature, which so far has not studied path dependency in industries with multiple technologies. At the same time, the study only includes three companies. Although they have dominated the industry for decades and still represent over $60 \%$ of the light source market, other industry participants (including more recent entrants) should be included in later studies in order to get a more complete picture of the industry.

In contrast to previous research, our study shows that different technologies that have coexisted over long periods of time can be conceptualized as multiple technological paths rather than a unitary cumulative progression (as the path notion is most commonly used in the existing literature). Indeed, the evidence in the form of strong technology-internal patterns of references and patent co-classification indicates that narrowly defined lighting technologies represent separate and largely parallel technological paths. At the same time, a positive interaction across these paths was recognized in the form of patent co-classification and presence of traditional classes in LED-related patents, including the two technology-specific classes associated with the incandescent and discharge paths. The complex pattern of inter-trajectory interaction needs to 
be explored further in future research, though. Here, inspiration can be taken from the literature on institutional paths, which has discussed multiple paths to a greater extent than the literature on technological path dependency.

The concept of multiple paths also extends the framework for analysis of the process of path creation. The unitary path concept implies that path dependent development can either lead to an inevitable lock-in (Vergne and Durand, 2010), or allow for the creation of new paths that replace old ones (cf. Araujo and Harrison, 2002; Garud et al., 2010). In neither of these cases is there any continuity between old and new paths. Instead, radical technological change is seen as discontinuous and primarily exogenously driven. In contrast, the concept of multiple paths recognizes that even radically new technologies can be partially based on previously existing paths. In the lighting technology field, a new technological path (LED) has emerged, which is an indication of a break with past activities and represents a divergent progression pattern from the point of view of the lighting industry. At the same time the incumbents' development of LED technology seems to be at least partially integrated with older lighting paths and builds to a large extent on previously accumulated knowledge, as evidenced by the use of traditional patent classes in LED patents. This indicates that there is an element of persistence, i.e. cumulative progression, also in the pursuit of this new, radically different technology. This implies that incumbent actors are not necessarily disadvantaged and that radical technical change can be endogenously driven. Moreover, path interaction can happen across different technological fields (semiconductor patents in lighting and in other technological fields), which is an especially promising opportunity for multi-technology companies.

Taken together, these findings add up to the overall conclusion that multiple technological paths can co-exist in companies and industries, characterized by simultaneous long-term presence of several technologies. In such cases, technological persistence - one of the central features of path dependency - can be seen both inside and across paths. We could see evidence of persistence at all the levels that were mentioned in the literature: technology (including a radically new LED technology), company and industry. However, further studies of selfreinforcing mechanisms are needed in order to assert that industries with multiple technological paths are not only persistent, but also path dependent, i.e. to go beyond establishing the existence of multiple paths (as we have done in this paper) and explain how paths emerge over time. Such studies would benefit from an innovation systems approach, which takes into account the sectoral specificities of the technological environment in which innovation takes place (Castellacci, 2007). When conducting these studies, implications of the multiple-path framework put forward in this paper should be taken into account by acknowledging both path-internal dynamics and cross-path patterns. This requires the analyst to consider multiple levels of analysis in parallel: technology, company and sector.

So far, there is no indication of lock-in of the studied companies. As evidenced by patent data, all the three companies are active in the new LED technology and, according to the available company and industry information sources, they have also developed LED products. However, LED technology is still in an early phase of development, which implies that the competitive outcomes of this discontinuous innovation are by no means clear yet. Further studies of selfreinforcing mechanisms and the incumbents' LED development strategies in comparison with the strategies of industry newcomers, with a particular focus on understanding the role and importance of traditional technological paths in LED development, might give an indication of 
the competitive advantages of each of these groups as well as the degree of path dependency of the lighting industry as a whole. Whether the observed patterns indicate a positive, "productive" path dependency and will help incumbents to stay in the lead through a process of creative accumulation (Bergek et al., 2013), or will lead to unsustainable lock-in by incumbents and an opportunity for new entrants to capture the lighting market thus remains to be seen.

\section{Funding}

The study on which this paper is based was partially funded by Riksbankens Jubileumsfond.

\section{Acknowledgements}

Comments from two anonymous reviewers, members of the KITE research group and two members of KITE's advisory board - Andy Van de Ven and Stefano Brusoni - are gratefully acknowledged.

\section{References}

Aminzade, R. (1992), 'Historical Sociology and Time', Sociological Methods \& Research, 20, 456480.

Antonelli, C. (2009), 'The economics of innovation: From the classical legacies to the economics of complexity', Economics of Innovation and New Technology, 18, 611-646.

Araujo, L. and D. Harrison (2002), 'Path Dependence, Agency and Technological Evolution', Technology Analysis \& Strategic Management, 14, 5-19.

Arthur, W. B. (1988), 'Competing technologies: an overview', in G. Dosi, C. Freeman, R. Nelson, G. Silverberg and L. Soete (ed.), Technical Change and Economic Theory. Pinter Publishers: London.

Arthur, W. B. (1989), 'Competing Technologies, Increasing Returns, and Lock-In by Historical Events', The Economic Journal, 99, 116-131.

Bergek, A. and C. Berggren (2004), 'Technological internationalisation in the electro-technical industry: a cross-company comparison of patenting patterns 1986-2000', Research Policy, 33, 1285-1306.

Bergek, A., C. Berggren, T. Magnusson and M. Hobday (2013), 'Technological discontinuities and the challenge for incumbent firms: Destruction, disruption or creative accumulation?', Research Policy, 42, 1210-1224.

Boschma, R. A. and K. Frenken (2006), 'Why is economic geography not an evolutionary science? Towards an evolutionary economic geography', Journal of Economic Geography, 6, 273-302.

Breschi, S., F. Lissoni and F. Malerba (2003), 'Knowledge-relatedness in firm technological diversification', Research Policy, 32, 69-87.

Brusoni, S., A. Prencipe and K. Pavitt (2001), 'Knowledge Specialization, Organizational Coupling, and the Boundaries of the Firm: Why Do Firms Know More Than They Make?', Administrative Science Quarterly, 46, 597-621. 
Bröring, S., L. Martin Cloutier and J. Leker (2006), "The front end of innovation in an era of industry convergence: evidence from nutraceuticals and functional foods', R\&D Management, 36, 487-498.

Cantwell, J. and G. Vertova (2004), 'Historical evolution of technological diversification', Research Policy, 33, 511-529.

Castellacci, F. (2007), 'Technological regimes and sectoral differences in productivity growth'.

Christensen, C. M. and R. S. Rosenbloom (1995), 'Explaining the attacker's advantage: Technological paradigms, organizational dynamics, and the value network', Research Policy, 24, 233-257.

Cowan, R. (1990), 'Nuclear Power Reactors: A Study in Technological Lock-in', The Journal of Economic History, 50, 541-567.

Cowan, R. and P. Gunby (1996), 'Sprayed to Death: Path Dependence, Lock-in and Pest Control Strategies', The Economic Journal, 106, 521-542.

Curran, C.-S. and J. Leker (2011), 'Patent indicators for monitoring convergence - examples from NFF and ICT', Technological Forecasting and Social Change, 78, 256-273.

D'Costa, A. P. (2002), 'Export Growth and Path Dependence: The Locking-in of Innovations in the Software Industry', Science Technology \& Society, 7, 51-89.

Danneels, E. (2002), 'The Dynamics of Product Innovation and Firm Competences', Strategic Management Journal, 23, 1095-1121.

David, P. A. (1985), 'Clio and the Economics of QWERTY', The American Economic Review, 75, 332-337.

Djelic, M.-L. and S. Quack (2007), 'Overcoming Path Dependency: Path Generation in Open Systems', Theory and Society, 36, 161-186.

Dobusch, L. and Schüssler (2012), 'Theorizing path dependence: a review of positive feedback mechanisms in technology markets, regional clusters, and organizations ', Industrial and Corporate Change, published online September 6, 2012 doi:10.1093/icc/dts029

Dobusch, L. and E. Schüßler (2012), 'Theorizing path dependence: a review of positive feedback mechanisms in technology markets, regional clusters, and organizations', Industrial and Corporate Change.

Dolata, U. (2009), 'Technological innovations and sectoral change: Transformative capacity, adaptability, patterns of change: An analytical framework', Research Policy, 38, 1066-1076.

Dosi, G. (1982), 'Technological paradigms and technological trajectories: A suggested interpretation of the determinants and directions of technical change', Research Policy, 11, 147162.

Essletzbichler, J. and L. Winther (1999), 'Regional Technological Change and Path Dependency in the Danish Food Processing Industry', Geografiska Annaler. Series B, Human Geography, 81, 179196.

European Commission (2011). Regulation (EC) No 139/2004. Merger procedure, Office for Publications of the European Union. 
Fagerberg, J., D. Mowery and B. Verspagen, Eds. (2009). Innovation, Path Dependency, and Policy. The Norwegian Case. Oxford University Press: Oxford.

Fai, F. and N. von Tunzelmann (2001), 'Industry-specific competencies and converging technological systems: evidence from patents', Structural Change and Economic Dynamics, 12, 141-170.

Fai, F. M. (2003), Corporate Technological Competence and the Evolution of Technological Diversification. Edward Elgar: Cheltenham.

Garud, R., A. Kumaraswamy and P. Karnøe (2010), 'Path dependence or path creation?', Journal of Management Studies, 47, 760-774.

Global Industry Analysts (2011), 'Lamps - a global strategic business report'.

Granstrand, O. (1994), 'Technology Diversification in "MUL-TECH" Corporations', IEEE Transactions on Engineering Management, 41, 355-364.

Helfat, C. E. and R. S. Raubitschek (2000), 'Product sequencing: co-evolution of knowledge, capabilities and products', Strategic Management Journal, 21, 961-979.

Henderson, R. M. and K. B. Clark (1990), 'Architectural Innovation: The Reconfiguration of Existing Product Technologies and the Failure of Established Firms', Administrative Science Quarterly, 35, 9-30.

HSBC Trinkaus\&Burkhardt (2011), 'A tectonic shift in the lighting industry ahead'.

Håkansson, H. and A. Waluszewski (2002), 'Path dependence: Restricting or facilitating technical development?', Journal of Business Research, 55, 561-570.

IBISWorld (2012), 'Lighting\&Bulb Manufacturing in the US'.

Karim, S. and W. Mitchell (2000), 'Path-dependent and path-breaking change: reconfiguring business resources following acquisitions in the U.S. medical sector, 1978-1995', Strategic Management Journal, 21, 1061-1081.

Karnøe, P. and R. Garud (2000), 'Path Creation and Dependence in the Danish Wind Turbine Field', in (ed.), The Social Construction of Industries and Markets Pergamon Press: Oxford.

Laursen, K. (1996), 'Horizontal diversification in the Danish national system of innovation: the case of pharmaceuticals', Research Policy, 25, 1121-1137.

Lei, D., M. A. Hitt and R. Bettis (1996), 'Dynamic core competences through meta-learning and strategic context', Journal of Management, 22, 549-569.

Mahoney, J. (2000), 'Path Dependence in Historical Sociology', Theory and Society, 29, 507-548.

Malerba, F. (2007), 'Innovation and the dynamics and evolution of industries: Progress and challenges', International Journal of Industrial Organization, 25, 675-699.

Malerba, F., L. Orsenigo and P. Peretto (1997), 'Persistence of innovative activities, sectoral patterns of innovation and international technological specialization', International Journal of Industrial Organization, 15, 801-826. 
Martin, R. (2010), 'Roepke Lecture in Economic Geography—Rethinking Regional Path Dependence: Beyond Lock-in to Evolution', Economic Geography, 86, 1-27.

Mazzoleni, R. (1997), 'Learning and path-dependence in the diffusion of innovations:

Comparative evidence on numerically controlled machine tools', Research Policy, 26, 403-428.

McKinsey\&Company (2011), 'Lighting the way: Perspectives on the global lighting market'.

Narula, R. (2002), 'Innovation systems and 'inertia' in R\&D location: Norwegian firms and the role of systemic lock-in', Research Policy, 31, 795-816.

Niosi, J. (2002), 'National systems of innovations are "x-efficient" (and x-effective): Why some are slow learners', Research Policy, 31, 291-302.

Osram (2012), 'The Global Lighting Industry: Tradition, Transition, Transformation', Presentation by Schraft, C. at the Strategies in Light EuropeConference in Munich.

Park, T.-Y. (2011), 'Path Dependence and the Incumbent's Survival in Cross Industries Under Radical Circumstances: Lessons From the Samsung Case', Engineering Management, IEEE Transactions on, 58, 154-164.

Parker, S. C. (2011), 'Intrapreneurship or entrepreneurship?', Journal of Business Venturing, 26, 19-34.

Patel, P. and K. Pavitt (1991), 'Large firms in the production of the world's technology: an important case of "non-globalisation"', Journal of International Business Studies, 22, 1-21.

Patel, P. and K. Pavitt (1997), 'The technological competencies of the world's largest firms: complex and path-dependent, but not much variety', Research Policy, 26, 141-156.

Philips (2011), 'Annual Report 2011'.

Poole, M. S., A. H. Van de Ven, K. Dooley and M. E. Holmes (2000), Organizational Change and Innovation Processes: Theory and Methods for Research. Oxford University Press: Oxford.

Rosenkopf, L. and A. Nerkar (2001), 'Beyond local search: boundary-spanning, exploration, and impact in the optical disk industry', Strategic Management Journal, 22, 287-306.

Rycroft, R. W. and D. E. Kash (2002), 'Path Dependence in the Innovation of Complex Technologies', Technology Analysis \& Strategic Management, 14, 21-35.

Sanderson, S. W., K. L. Simons, J. L. Walls and Y. Lai (2008), 'Lighting', in J. T. Macher and D. C. Mowery (ed.), Innovation in Global Industries: US Firms Competing in a New World (Collected Studies). The National Academic Press: Washington, D.C.

Schneiberg, M. (2007), 'What's on the path? Path dependence, organizational diversity and the problem of institutional change in the US economy, 1900-1950', Socio-Economic Review, 5, 4780 .

Schreyögg, G., J. Sydow and P. Holtmann (2011), 'How history matters in organisations: The case of path dependence', Management \& Organizational History, 6, 81-100.

Silverman, B. S. (2004), 'Documentation for International Patent Classification - U.S. SIC concordance'. Retrieved 10.05, 2012, from 
http://www.rotman.utoronto.ca/ silverman/ipcsic/documentation IPC-

SIC concordance.htm.

Simmie, J. (2012), 'Path Dependence and New Technological Path Creation in the Danish Wind Power Industry', European Planning Studies, 20, 753-772.

Storz, C. (2008), 'Dynamics in innovation systems: Evidence from Japan's game software industry', Research Policy, 37, 1480-1491.

Sutherland, L.-A., R. J. F. Burton, J. Ingram, K. Blackstock, B. Slee and N. Gotts (2012), 'Triggering change: Towards a conceptualisation of major change processes in farm decision-making', Journal of Environmental Management, 104, 142-151.

Sydow, J., G. Schreyögg and J. Koch (2009), 'Organizational path dependence: opening the black box', Academy of Management Review, 34, 689-709.

Sydow, J., A. Windeler, C. Schubert and G. Möllering (2012), 'Organizing R\&D Consortia for Path Creation and Extension: The Case of Semiconductor Manufacturing Technologies', Organization Studies, 33, 907-936.

Teece, D. J., G. Pisano and A. Shuen (1997), 'Dynamic capabilities and strategic management', Strategic Management Journal, 18, 509-533.

Thrane, S., S. Blaabjerg and R. H. Møller (2010), 'Innovative path dependence: Making sense of product and service innovation in path dependent innovation processes', Research Policy, 39, 932-944.

Tushman, M. and P. Anderson (1986), 'Technological Discontinuities and Organizational Environments', Administrative Science Quarterly, 31, 439-465.

Unruh, G. C. (2000), 'Understanding carbon lock-in', Energy Policy, 28, 817-830.

Van den Daele, L. D. (1969), 'Qualitative models in developmental analysis', Developmental Psychology, 1, 303-310.

Vergne, J. P. and R. Durand (2010), 'The missing link between the theory and empirics of path dependence: Conceptual clarification, testability issue, and methodological implications', Journal of Management Studies, 47, 736-759.

Woodside Capital Partners International (2012), 'Research Report: LED Lighting'. 


\section{Appendix A. Patent search strategy}

\begin{tabular}{|c|c|}
\hline Search string & Basis for inclusion \\
\hline $\begin{array}{l}\text { An/CompanyName and (icl/H01J61/\$ or } \\
\mathrm{icl} / \mathrm{H} 01 \mathrm{~J} 63 / \$ \text { or icl/H01J65/\$) }\end{array}$ & $\begin{array}{l}\text { - one of Osram's most important classes } \\
\text { - used in Sanderson et al (2008) } \\
\text { - class description: discharge lamps }\end{array}$ \\
\hline $\begin{array}{l}\text { An/CompanyName and (icl/H05B31/\$ or } \\
\text { icl/H05B33/\$ or icl/H05B35/\$ or icl/H05B37/\$ } \\
\text { or icl/H05B39/\$ or icl/H05B41/\$ or } \\
\text { icl/H05B43/\$) }\end{array}$ & $\begin{array}{l}\text { - one of Osram's most important classes } \\
\text { - used in Sanderson et al (2008) } \\
\text { - class description: lighting }\end{array}$ \\
\hline An/CompanyName and icl/F21\$ & $\begin{array}{l}\text { - one of Osram's most important classes } \\
\text { - derived from Silverman (Silverman, 2004) } \\
\text { - class description: lighting }\end{array}$ \\
\hline An/CompanyName and icl/C09K11\$ & $\begin{array}{l}\text { - one of Osram's most important classes } \\
\text { - class description: luminescent, e.g. } \\
\text { electroluminescent, chemiluminescent, materials }\end{array}$ \\
\hline An/CompanyName and (icl/H01K\$) & $\begin{array}{l}\text { - used in Sanderson et al (2008) } \\
\text { - class description: incandescent lamps }\end{array}$ \\
\hline An/CompanyName and (icl/260\$ or icl/2699) & $\begin{array}{l}\text { - one of Osram's most important classes } \\
\text { - class description in international classification for } \\
\text { industrial design patents: lighting apparatus }\end{array}$ \\
\hline $\begin{array}{l}\text { an/CompanyName and (ttl/("LED" or "LEDs" or } \\
\text { "L.E.D." or "L.E.D.s" or "light emitting diode" or } \\
\text { "light emitting diodes" or "light-emitting diode" or } \\
\text { "light-emitting diodes" or "light-emitting-diode" } \\
\text { or ") or abst/("LED" or "LEDs" or "L.E.D." or } \\
\text { "L.E.D.s" or "light emitting diode" or "light } \\
\text { emitting diodes" or "light-emitting diode" or } \\
\text { "light-emitting diodes" or "light-emitting-diode")) }\end{array}$ & $\begin{array}{l}\text { - all key words related to LED, used as } \\
\text { complementary to search per H01L class name } \\
\text { - used in Sanderson et al (2008) }\end{array}$ \\
\hline $\begin{array}{l}\text { an/CompanyName and (ttl/("lighting" or "lamp" } \\
\text { or "lamps" or "light source") or abst/("lighting" or } \\
\text { "lamp" or "lamps" or "light source")) }\end{array}$ & $\begin{array}{l}\text { - lighting and lamp used as complementary to search } \\
\text { per class name }\end{array}$ \\
\hline
\end{tabular}

Instead of CompanyName, the following were used:

- General Electric or GE

- Subsidiaries of General Electric:

- Tungsram (since 1989)

○ Gelcore

- For the following subsidiaries 0 relevant patents found

- PT Sinar Bary Electric (SiBalec) (since 1996)

- Flame Electrical Ltd. (since 1997)

- Ecolux (since 2000)

- Osram or Siemens

- Subsidiaries of Osram:

- Patent Treuhand $\mathrm{GmbH}$

- Sylvania (since1992)

- For the following subsidiaries 0 relevant patents found

- TESLA Nové Zámky (since 1995) 
- CNZ (since 2001)

- Svet (since 2004)

- Philips

- Subsidiaries of Philips (after the year of acquisition when relevant)

○ Lumileds

- Genlyte (since 2007)

- Ilti Luce (since 2009)

- For the following subsidiaries 0 relevant patents found

- ECS (since 2000)

- Lumisistemas (since 2001)

- Helfont (since 2001)

- The Bodine Company (since 2006)

- Partners in Lighting International (since 2006)

- Color Kinetics (since 2007)

- Vancouver (since 2007)

- Lighting Technologies International (LTI) (since 2007)

- Dynalite (since 2009)

- Teletrol (since 2009)

- TIR Systems

- Selecon (since 2009) 